\title{
The Impact on Electronic Commerce Activities of SMEs: A Study of the Turkish Automotive Supplier Industry
}

\author{
Muammer Zerenler \\ Esen Şahin \\ Selçuk University Konya
}

Doi:10.5901/ajis.2013.v2n9p69

\begin{abstract}
This study aims to investigate the issues of electronic commerce activities in small and medium sized enterprises as a consequence of organizational change initiated by the adoption of information technologies. The fundamental issues influencing electronic commerce practices of SMEs are their insufficiency of cognitive learning and organizational strategy, financial and distribution problems specific to SMEs, limitations of supply chain management, reluctance of organizational culture for electronic change, problems of information technologies usage, insufficiency of human resource, resistance of top management to organizational change as required by the adoption of information technologies, integration problems of new technologies with the existing systems, lack of confidence on the side of customers towards electronic commerce. A study of the Turkish Automotive Supplier Industry has revealed that electronic commerce has been adopted and its benefits are accepted. However, the industry has to overcome some technical and managerial difficulties to implement it more efficiently and effectively.
\end{abstract}

Keywords: Electronic commerce, SMEs, automotive supplier industry, information technology, integration problem, organizational culture, cognitive learning, Turkey.

\section{Introduction}

In societies where commercial competition is accepted as an economic system, there is a close relationship between the healthy operation of the system and the existence and power of small and medium sized enterprises (SMEs) within the system. Most SMEs positively contribute to the system since they can fulfill several functions not achieved by large enterprises (MacGregor, 2004, p. 10).

SMEs are not merely economic elements; they also have vital roles in social life. Because of the fact that SMEs spread to a large area in the country, they act as a critical power in lessening regional developmental differences, spreading ownership to a vast area, creating and sustaining employment opportunities, and keeping democratic life alive.

Currently, SMEs play a fundamental role in terms of employment and macro- economic balance by increasing their shares in global economy and thus enabling high levels of employment. Overall contributions of SMEs to the economy can be outlined as the following: (Kleindl, 2000, p. 75; Walczuch et al., 2000, p. 568):

- Depending on labor intensive work and efficiency in resource use, they contribute to creating employment opportunities and lessening unemployment nationwide.

- They adapt quickly and comfortably to demand changes and variations.

- They help to balance income distribution.

- They enable making decisions quickly. Since they are mostly structured as family companies, there is a tendency to make centralized decisions (Evans and Wurster, 1997, p. 72).

- In the long run, they are in a position to become manufacturers of the inputs and intermediary goods of large industrial enterprises.

- They are flexible and supportive of innovations.

- They are effective in improving life quality by providing opportunities for the socially and politically disregarded labor force, raw materials and financial sources to operate by smaller investments (Levy et al., 1999, p. 249).

- They acquire a critical role in transmitting small funds and family capital directly to investments.

- Through manufacturing inputs such as raw materials, intermediary materials, and semi-finished products consumed by large scale enterprises, they contribute to their development and also the national economy. 
- They contribute significantly to increasing regional employment opportunities since they are labor intensive; therefore prevent migration from small cities to big city centers and construct a base for self development of the region within its own potential.

- By positively affecting income distribution, preventing the accumulation of capital in the hands of large industrial organizations or a minority, they increase societal income both functionally and regionally.

SMEs are also effective in providing new ideas and inventions and adopting new technologies (Kleindl, 2000, p. 76). New technologies enable SMEs to perform more creatively and flexibly with lower costs. Small enterprises are effective in transferring various technologies to national economy and in the process of modernization traditional technology or adaptation to the transferred technology; they act as a bridge between new and traditional technologies (Evans and Wurster, 1997, p. 74). On the other hand today, the rapidly increasing automation and demand for more qualified employees force SMEs to adopt new technologies. SMEs face difficulties, basically due to lack of sources, in following new technologies, acquiring technological materials, finding and employing qualified technical personnel to implement new technologies. Qualified employees generally prefer job security of large enterprises, corporate reputation, and high salaries.

The ability of SMEs to survive in a highly competitive environment depends on the extent and speed in activating the changes that will make their products and / or services noticeable and preferable. As SMEs achieve these goals in establishing and sustaining enterprise's relationship with the outer world by benefiting from the opportunities of technology, they make use of information technologies and its elements. At this point electronic commerce is helpful in achieving innovations and improvements rapidly and safely (Hawkins and Prencipe, 2000, p. 24).

\section{SMEs and Electronic Commerce}

While globalization and technological changes create new opportunities for SMEs, at the same time they create new risks and threats. It is considered that SMEs, due to their flexibility, can meet customer expectations more quickly and they are more advantageous than large enterprises in utilizing electronic commerce (Dandridge, 2000, p. 87; Daniel et a., 2002, p. 261). Because of competition and pressures of software providers and system integrators, several SMEs search for new ways to increase their market shares by implementing electronic commerce solutions. Besides, while large companies already have necessary personnel and financial sources to implement electronic commerce, capital limitations of SMSs restrict their investments for electronic commerce (Stansfield and Grant, 2003, p. 16).

On the basis of discussions so far, it is possible to summarize the contributions of electronic commerce to SMEs as the following. Electronic commerce enables SMEs to enter new markets and thus competition gains impetus. Since it speeds up operations and lessens demand for labor, it decreases costs. As it provides effective communication between buyers and sellers, it helps to improve service and product quality. Enhancing data share it contributes positively to the efficiency of work processes and overall economy (Eikebrokk and Olsen, 2007; Van Beveren, 2002; Levy et al., 1999).

Generally speaking, all of the contributions listed above can be deemed convincing. For instance the fact that with a lower investment SMEs can reach the markets which they can never attain through other ways seems rather feasible. Yet when this issue is discussed elaborately, the matter surfaces in a more complicated manner. Quite probably SMEs will face a difficulty in employing qualified human resources that can develop the information system within its own structure. In that case, the enterprise will be forced to employ people / companies out of the enterprise for the sales website. Employing people outside the enterprise makes it difficult to have a flexible and expandable performance applicable in their own sector. The fact that system is established / organized in a separate location will bring drawbacks in terms of updating and securing commercial safety (Dans, 2001, p.77). As it is illustrated in this scenario, several cultural, economic and commercial reasons may hinder SMEs' electronic commerce performance. Let aside all these points, it is not for certain that even a well prepared website - or other digital tools, can immediately find a market or open inaccessible markets (Liew, 2009, p.17).

Successful implementation of electronics is related to a multivariate and complicated process, which is connected with social and economic elements as much as with technical, technological, physical and legal infrastructure. In this section, the objective is to comparatively analyze the factors that affect / prevent SMEs' successful implementation of electronic commerce activities and to discuss sample cases unique to several SMEs operating in different sectors.

\section{The Effects of Electronic Commerce Applications in SMEs}

Electronic commerce provides important opportunities to SMEs in reaching new markets and competing with rivals. 
Virtual shops on internet enable SMEs to reach distant markets by offering an effective and economical marketing channel. Therefore SMEs obtain a chance to enter global markets without necessitating high investments and expenditures and offer inexpensive, fast, and high quality products in these markets (Evans and Wurster, 1997:77). On the other hand product development and marketing processes are shortened in SMEs, where electronic commerce is actively used. In the past, thanks to the application of information technologies, SMEs that followed / copied large scale enterprises, obtained critical time advantages in product development and marketing processes (Heijden, 2000, p. 41; Walczuch et al., 2000, p. 570; Levy et al., 1999, p. 252; Coppel, 2000, p. 17; Porter, 2001, p. 67).

Regardless of the fact that electronic commerce contains in itself various advantages for SMEs, still it is hardly possible to assert that SMEs make enough use of electronic commerce. Researches on this issue reveal that SMEs generally use Internet as a basic communication means and regard it as an alternative communication tool that cuts off costs more than traditional communication mediums such as fax and telephone (Kleindl, 2000, p. 78; Fisher, 2000, p. 61; Soliman and Yousef, 2003, p. 548).

It is clear that job opportunities for electronic commerce provided to SMEs vary at different levels for each sector. Among the reasons, there are the type of commerce, technological infrastructure of the country, Internet utilization ratio, and cognitive literacy. Within this scope it is crucial that SMEs take into consideration several factors effective in their investments for electronic commerce. These factors can be outlined in general as the following issues (Liew, 2009, p. 25):

Target market and geographical region where business is concentrated: Today a great majority of SMEs produce for national markets and most of the exporting enterprises also have domestic market oriented commercial expansion. Orienting towards foreign markets by using electronic tools and methods renders it a requisite for an enterprise to change its basic job performance applications such as product marketing, managing customer relations, and securing after-sales customer assistance (MacGregor, 2008, p. 47).

Products and services offered through electronic channels: Enterprises in developed countries have required infrastructure and sufficient experience in selling products and services through electronic commerce. Electronic commerce can be effectively activated particularly in service industries, where information provides significant added value.

Internet based commerce opportunities and compatibility of production chain systems as business development method: A good deal of industrial products may not be suitable for direct sales on Internet. The reasons may be specified such that seller has a limited number of buyers with web page access, physical contents of product, specific features of product, or restrictions for marketing. Considering the fact that enterprises will keep on using traditional marketing and distribution methods, holding a position on web and catalogues, being a part of commercial opportunities and presentation chain webs can be valued as supportive services for commerce (Van Beveren, 2002, p. 253).

A research - Digital Marketing Compass - conducted in the beginning of 2009 focused on substantial investments, budget plans for future, and attitudes concerning electronic marketing of the total 783 decision makers. In Digital Marketing Compass, unlike many studies on electronic marketing, it has been pointed out that not only "large scale" companies, but also SMEs increased their electronic marketing investments a significant amount. According to the research, various opportunities provided through electronic marketing is generally known well by SMEs and used appropriately. In 2008 web based marketing utilization was 32\%. The most striking outcome of this research is related to the orientation of SMEs towards international markets. Electronic based marketing activities of export-oriented SMEs were ahead of traditional marketing methods in 2008 (http://www.ogilvy.com.tr/digitalmarketingcompass/).

Cost and suitability of Internet access / hosting services: Under the condition that Internet access costs are reasonable, enterprises will more extensively use electronic mail, which is faster and less expensive than communication by telephone and fax. Besides, the costs of creating and supporting a website increase in line with the contents of site and the level of applied technology (Sadowski, 2002, p. 80; Quayle, 2002, p.1151).

The cost of accessing data for the market and potential partners: Private websites offering commercial data perform this mission in return for a certain price, which may be unaffordable for some SMEs. However, most public institutions provide supportive information for commerce free on Internet. Sustaining these services and reducing the cost of paid services in the long run will help SMEs to detect their target markets, access reliable data concerning their partners, determine the correct distribution channels, learn legal and regulative rules, reach financial sources, risk management, and logistic services (Colombo, 2001, p. 179).

Moreover particularly for SMEs with a unique product and operation model, it will be possible to finance electronic commerce investments in a short period. Because the extensive size of the market achieved through electronic commerce provides a market these enterprises can never reach with the help of traditional methods. Freeing themselves from the obligation of being local can create a global-scale breakthrough for companies with the best product and business performance (Stansfield and Grant, 2003, p. 17) 


\section{The Problems Affecting Electronic Commerce Activities of SMEs}

The basic problems affecting electronic commerce applications of SMEs are inadequacy of cognitive learning and organizational strategy, financial and distribution problems specific to SMEs, restrictions in supply chain management, reluctance of organizational culture for electronic transformation, problems in the application of information technologies, lack of qualified personnel, resistance of top management against organizational transformation necessitated by applying information technologies, integration problem of new technologies with available systems, customers' lack of trust towards electronic commerce, and their worries concerning privacy (Vinberg, et al. 2000; Oyelaran-Oyeyinka and Kaushalesh Lal, 2006).

Janenko (2003) believes that one of the most important problems SMEs face in electronic commerce activities is "automatic success deception". According to Janenko, many SMEs have automated several aspects of their work processes through websites and are convinced that success will come automatically (2003). Varianini and Vaturi (2000) have found out similar causes for the problems affecting digitalizing process of SMEs such as to sustain a fixed market information flow, not possessing a flexible organization structure, not detecting clear targets, and lack of safety and integration. Farhoomand and Lovelock (2001) also, has discovered numerous negative elements affecting electronic commerce in SMEs such as poor income / outcome / profit model, lack of competition advantage, insufficiency in providing benefits to customer, organizational problems, and the conflict between website and current business partners.

As stated by Kshetri problems affecting electronic commerce negatively are mostly concentrated on economic and social areas (2007, p. 446). Economic problems can be outlined as low level of information technology applications, inadequacy of Telecom infrastructure, lack of capital, low level of credit card usage. The social problems are low level of cognitive literacy, foreign language (mainly English) insufficiency, promotion and marketing problems of local websites.

According to Kshetri the problems affecting electronic commerce can be categorized under three groups such as pre-electronic commerce, in electronic commerce processes, and post-electronic commerce (2007, p. 447). Preelectronic commerce problems are mostly related to the adequacy of a country's cognitive infrastructure. Credit card usage nationwide and financial problems are observed in the electronic commerce process phase. Post-electronic commerce problems are distribution infrastructure and after-sales services. Within a macro point of view, Kshetri bases this grouping mostly to the technical problems associated with information infrastructure of countries. Peterson et al. (1997, p. 337) classify problems in electronic commerce as financial, legal, infrastructure, safety, customer privacy, protection of intellectual and industrial rights, problems faced during delivery, and customs operations. Dornan (2001, $p$. 27) on the other hand groups problems affecting electronic commerce just like Peterson et al.

While some authors point out that in electronic management activities of SMEs, efficiency of non-commercial based transformation will increase, traditional commerce will at the same time affect / delay / repress the development of electronic commerce activities (Heinen, 1996; Chaffey, 2007, Li, 2006; Chen and Siems, 2001; Sadowski, 2002). Some authors advocate that the development of electronic commerce in the entire organization will be experienced faster at the end of e-commerce based transformation process (Jelassi and Enders, 2008; Bayles, 2001; Strader and Ramaswami, 2002).

According to McGregor and Vrazalic in terms of adopting electronic commerce, SMEs can be categorized into two groups such as potential adopters and non-adopters. The non-adopter group cannot use electronic commerce due to internal causes of enterprises and external causes related to technological, economic, politic, legal, social, and cultural problems $(2006$, p. 7). Kapurubandara and Lawson advocate that in overcoming these obstacles methodologically "decision taking" and "adoption" processes take place (2006, p.2). Stockdale and Standing categorize all the factors under four main groups such as "lack of resources and data, skill levels of employees, safety issues and preparation of small enterprises" (2004). Kurnia and Johnson include supply chain structure in this grouping as well (2000). In Table 1, it is possible to summarize the different views mentioned above.

Table 1. Review of Literature

\begin{tabular}{|l|l|}
\hline $\begin{array}{l}\text { High cost of electronic commerce tools, } \\
\text { hardware/software cost of Internet technology. }\end{array}$ & $\begin{array}{l}\text { Jacovou (1995), Quayle (2002), Puaro and Campbell (1998), } \\
\text { Lawrance (1997), Riquelme (2992) and Van Akkeren and } \\
\text { Cavaye (1990) }\end{array}$ \\
\hline Problems originating from size of small enterprises. & Webb and Sayer, (1998), Van Beveren, (2002) \\
\hline Closeness to innovation and information technologies. & Van Beveren, (2002), (Davis, 2000), Dandridge, (2000) \\
\hline Adoption problems to electronic commerce. & Walczuch et al., (2000), Webb and Sayer, (1998) \\
\hline Complex structure of electronic commerce. & Quayle (2002), Chaston, (2001). \\
\hline
\end{tabular}




\begin{tabular}{|l|l|}
\hline $\begin{array}{l}\text { SMEs' family company structure and lack of } \\
\text { institutionalism. }\end{array}$ & Dandridge, (2000), Sadowski, (2002), Colombo, (2001). \\
\hline $\begin{array}{l}\text { While SMEs have development necessity in a short term, } \\
\text { the fact that electronic commerce acquires its feedbacks } \\
\text { only in the long run. }\end{array}$ & Lawrance (1997)and McGowan and Madey (1998) \\
\hline $\begin{array}{l}\text { Low level of cognitive literacy among employees and } \\
\text { resistance. }\end{array}$ & Lawrance (1997), Van Akkeren and Cavaye (1999) \\
\hline $\begin{array}{l}\text { Preferring traditional methods such as telephone, fax, } \\
\text { and face-to-face communication. }\end{array}$ & $\begin{array}{l}\text { Lawrance (1997), Vankatesan and Fink (2002) and Poon and } \\
\text { Swatman (2000) }\end{array}$ \\
\hline $\begin{array}{l}\text { Safety problem of electronic commerce. } \\
\text { Quayle (2002), Puaro and Campbell (1998), Riquelme (2002), } \\
\text { Van Akkeren and Cavaye (1999), Poon and Swatman (2000) } \\
\text { and Hadjimonolis (1999). }\end{array}$ \\
\hline $\begin{array}{l}\text { Lack of integration among customers, suppliers and } \\
\text { business partners who all have critical roles in } \\
\text { implementing electronic commerce. }\end{array}$ & \begin{tabular}{l} 
Hadjimonolis (1999), McDonagh, (2000) \\
\hline $\begin{array}{l}\text { Lack of adequate trust towards external consultancy } \\
\text { firms }\end{array}$
\end{tabular} \begin{tabular}{l} 
Lawrance (1997), Van Akkeren and Cavaye (1999), Chau and \\
\hline Turner (2001).
\end{tabular} \\
\hline
\end{tabular}

Source: Robert C.MacGregor, Lejla Vrazalic, "A Basic Model of Electronic Commerce Adoption Barriers", School Of Economics and Information Systems, University of Wollongong, Australia, p. 515

In this study, we evaluate the problems affecting successful electronic commerce applications of SMEs - as it is widely accepted in relevant literature; under two groups such as cultural and technical problems (Rowley, 2002; Warren and Hutchinson, 2005; Gottschalk, 2005; Combe, 2006).

\section{Cultural Problems}

\subsection{Top Management Support:}

Management support is the driving force in electronic commerce applications in corporations. According to Delone top management support is the most crucial factor for information technology applications in SMEs (1988). In particular, without the support of top management in decision-making process, it is not possible for SMEs to realize structural and technological transformation in electronic commerce by making required decisions and moreover without their support, any initiative regarding this matter may become unsuccessful (Grandon and Pearson, 2004).

\subsection{Imperfect Entrepreneurship:}

Social habits originating from the past of a country are among the main factors determining the implementation speed and form of new technological developments. These habits, which determine the confidence of people to their environment and economy, particularly to money earning process, are also basic causes lying behind economic differences among countries.

\subsection{Unsuitability of organizational culture for electronic commerce:}

One of the potential problems almost any organization aiming electronic commerce implementation is that organizational culture may not be suitable for organizational transformation necessitated by electronic management. Technological transformation and electronic business environment as required by electronic commerce will cause vital changes such as developing infrastructure and training activities compulsory particularly for organizations where bureaucratic work is dominant (Chen, 2004).

\subsection{Ambiguity of benefits:}

Another problem for SMEs is the ambiguity of benefits that will be gained through electronic commerce implementation. 
Since electronic commerce is a recent phenomenon, it is hard to compare successful examples of SMEs. Small enterprises in particular are inclined to be more influenced by tangible practice results rather than theoretical knowledge.

On the other hand, although it can be possible for almost any field, electronic commerce may have high success in certain products but low in others. For instance in intangible goods such as music, software etc. that can be easily transmitted from one place to another through websites, electronic commerce provides numerous advantages. However, for products which are hard to be transmitted physically, the advantages of electronic commerce are relatively limited (Levy et al., 1999, p. 244).

\subsection{Innovativeness and insufficiency of innovation management}

According to Zhao, similar electronic management applications that have become widespread in companies decrease the effectiveness of competition tools. They seriously differ from traditional business models, and their advantages and similarities reduce benefits of suppliers and customers (2006). Since innovation strategies in electronic management applications will provide quick and flexible dynamism necessitated by the demands of shareholders and electronic transformation, SMEs will have to prioritize their innovative activities (Singh and Waddell, 2006).

\subsection{Difficulty of changing shopping habits:}

This problem is particularly valid in countries where traditional life style is dominant. Transformation in shopping habits takes place at a slower pace than economic commerce development of any country. It is common that people prefer to buy from people they already know after seeing and touching goods. Shopping from a virtual environment, not knowing the nature of the product or its delivery conditions may not be quite acceptable for some people.

On an Internet shoe seller zappos.com established in 1999, there are more than 3 million pairs of shoes. One of the most important features of this company which ensures 365 day refund guaranty is its free cargo service for both customer deliveries and returns. Seventy-five percent of all orders come from satisfied customers. Following his / her first shopping a customer makes 2.5 times more shopping in the next 12 months after the first order. Forty-three percent of the recently gained customers are from WOMM (word of mouth marketing) process. They provide a toll-free call line. Unlike other big e-commerce sites (Amazon, overstock, e-bay etc.) they place their number on each page. If their product does not meet the requirements of customers, they recommend other competitor sites. So far none of its customers, by providing their name or no name, has made any complaints (www.zappos.com).

\subsection{Locality:}

For enterprises, one of the most significant economic developments introduced by Internet is the expansion of local markets to a global scale. Economic activities such as web-based advertisements, promotions, job offers, marketing activities, and sales are accessible for any Internet user enterprise and customers. Thus, it becomes easier for enterprises expanding towards foreign markets to sustain and enlarge their activities. Besides it is regarded as an opportunity not to be missed for medium and small sized enterprises, which have fully utilized foreign market potential (Reynolds and Mofazali, 2000; Combe, 2006).

\section{Technical Problems}

\subsection{Inadequacy of human resources:}

Human resources management approach and its applications have now become effective in a new field described as electronic human resource by the influence of information technologies. Basically electronic human resource concept means supporting human resources management approach by a new structuring in the electronic environment. It is viewed as a way to support human resource oriented strategies, policies, and applications through Internet based channels (Williamson et al., 2003, p.247).

As an outcome of current use of information technologies in enterprises, new employment opportunities emerge in the relevant sectors, and demand for expert technology personnel increases in return. However, throughout the world parallel to the fast development of electronic commerce, new job opportunities and demand for human resource increase, but the supply of qualified human resource does not grow at the same pace (Lai and Chen, 2009). 
Electronic commerce applications require changes in the commercial and organizational structures and qualifications of personnel. In several countries, lack of information personnel has turned out to be a critical problem. Although it is early to make a guess on the future demand for qualified labor force, it can be regarded as an indicator that of all the personnel working in electronic commerce related enterprises, an average of $45-50 \%$ are employed in sales and marketing, 25-35\% in research-development, and the rest in management, finance, and other areas (Zerenler, 2007, p. 223).

\subsection{Insufficient marketing strategies:}

The popularity of electronic commerce as a business medium is related to the capacity of Internet, namely its future potential, its attractive qualities, its dynamism in providing global share of information and resources, and Internet's power in offering an effective channel of advertisement, marketing and direct distribution of certain products and / or services. In his book titled "Supra-Competition" Edward de Bono states "despite everything you must not fall behind your rivals otherwise you cannot sustain your presence. Price, quality, product differentiation and setting special markets are all traditional mediums serving this objective" (1994, p. 27). Indeed, enterprises competing in today's modern world are obliged to implement electronic based marketing activities, which have turned out to be a necessity rather than an advantage in competition that is becoming increasingly violent and different. Thus in such an environment where even electronic commerce is dedifferentiated, followed, and imitated by rivals, differentiating electronic marketing to adapt them to the basic qualities of enterprise would reply to the predictions of Bono, namely being supra-competition.

Electronic marketing is regarded as a revolutionary tool transforming all business processes of enterprises. Electronic marketing also, causes transformation of the traditional market structures (Calin et al., 2001, p. 36). The central role of this transformation belongs to Internet. Internet's progress is the most vital determinant of electronic marketing development. In addition, electronic marketing transforms purchase decision process of buyers as well. As buyers get involved in electronic marketing, they catch a chance to examine more options than traditional markets and thus able to make quicker decisions.

The fact that electronic commerce is full of opportunities for enterprises and it has risk minimizing quality account for the reasons not to be used. The answer for the question how to use and how to make the best of it, is related to strategy formulation. Fearing that other enterprises will seize their own markets through Internet and planning the cost of not using Internet as a defense reflex, several enterprises choose to find methods to use Internet more effectively. To achieve this end, conscious application and marketing strategies unique to Internet use should be developed (Zerenler, 2007, p. 267). If electronic commerce or cognitive business processes are, above all, established on the information bases of sector and markets, then these enterprises starting business without sufficient pre-researches may face failure. To make a right start, it is a must that enterprises planning to operate in this field should conduct pre-researches and also forms the required information infrastructure.

\subsection{The size of enterprise and lack of knowledge:}

Parallel to the phase of entering information based economy, for the purpose of adapting SMEs to the new work conditions introduced by this economic system, both national governments and international corporations initiated activities to inform enterprises about electronic commerce. A great majority of relevant literature points out the fact that in most countries, except USA, a great portion of SMEs is not yet totally aware of electronic commerce benefits (Coppel, 2000, p. 71). On the other hand, some authors hold the view that enterprise size also, has an effect over cognitive literacy and electronic commerce competency. As the enterprises get smaller in size, it is witnessed that Internet use that constitutes the base of electronic commerce falls backward. According to a research conducted by Levy et al., in enterprises with more than 1000 workers Internet usage ratio reaches to a level of $42 \%$, whereas this ratio decreases to $14 \%$ for SMEs employing 1-49 workers (2001, p. 135).

\subsection{Inability of managing technology:}

Selecting the technology required by SMEs to achieve their strategic and short-term goals, planning the required technology applications, deciding for transfer or manufacturing and realizing the activities for implementing this decision within the framework of a plan and program are among the basic activity issues of technology management. Strategic technology selection and goal-oriented work planning will ensure successful application of technology management. 
Although electronic commerce offers wider range of opportunities for enterprises where information technologies are intensively implemented or manufactured, the very same advantage is hard to be viewed in the sectors far away from these technologies. In short, sector features may be restrictive in electronic commerce applications (Zhao, 2006, p.47).

\subsection{Language and cultural elements:}

In the Internet environment, making it possible to access resources from all over the world, it is observed that language and cultural elements also demonstrate significant effects. Although $70 \%$ of Internet contents are in English, half of Internet users do not understand English. Still as stated by Coppel, even without this language problem, customers are more eager to shop from websites in their native tongue (2000, p.21).

English that is spoken like a native language in almost any international activity is dominant in electronic management operations as well. Yet companies marketing to regions where Spanish, Chinese, and Urdu languages are common should direct their marketing activities by taking regional languages into account.

Aside from the language problem, cultural elements also greatly affect electronic commerce activities of SMEs. Since many visual elements from colors to symbols present cultural differences among societies, many SMEs willing to benefit from global nature of Internet encounter difficulties.

\subsection{Infrastructure and Environmental Problems:}

The foundation of electronic commerce is structured over communication infrastructures and information technologies. Particularly in developing countries communication costs are high and technological infrastructure falls short. High communication cost is one of the most important problems in electronic commerce applications. Generally, it is possible to comment the following suggestions for solving infrastructure problems (Reynolds and Mofazali, 2000, p.81-83; Chen, 2004, p.161):

- Telecommunication infrastructure should be improved; and it should be possible for SMEs to benefit from these services in private.

- All forms of electronic commerce; particularly commerce through Internet, can be conducted by providing information flow through communication infrastructure. In cases where only Internet centered structuring is an issue, potential cutbacks and problems on Internet may cease commerce. Hence, alternative connection forms should be structured.

- The obstacles keeping communication and markets of information technologies away from competition should be abolished.

- Technical standards in communication should be determined.

- Environment of confidence should be established for service providers, users, and consumers taking place in electronic systems and operations.

\subsection{Connection problems:}

Connection problems are among the most frequently faced obstacles on Internet in electronic commerce applications. This problem, which does not merely restrict electronic commerce but all types of Internet use, is a deficiency causing information access efforts to become fruitless (Nusair and Hua, 2009).

There are attempts to simplify Internet connection and increase the access speed of countries. Failure to provide an effective infrastructure and telecom activities, which are public in many countries, restrict the operations of private sector. Restricted activities introduce high costs, poor quality yet costly access options. Recently the attempts to enable access through satellite and improving the present options by using high quality cables have been speeded up by private sector.

\subsection{Legal problems:}

Legal problems are the foremost reason critically determining the transformation of electronic commerce implementation into a global structure. Many issues such as the validity and binding of a computer based contract, validity of data kept in computer environment and their power of evidence, validity and applicability of digital signature, protection of intellectual and artistic works on Internet environment, legal recognition of information based crimes and prevention of unfair 
competition affect SMEs greatly. The main legal problems in electronic commerce applications can be outlined as the following (Kalakota and Whinston, 1997, p. 33):

a) Intellectual ownership rights,

b) Taxation,

c) Approval procedures,

d) Deficiencies in international laws,

e) Privacy rights of people,

f) Validity of electronic documents problem,

g) Validity of digital signature problem,

h) Determining responsibilities of service providers,

i) Necessity to review laws by considering electronic environments,

Although so far insignificant developments have been achieved in universalizing legal infrastructure of electronic management operations among countries in areas such as digital signature, reliable third party, information management and safety, information crimes and coordination of electronic commerce, still some critical legal expansions have been achieved.

\subsection{Safety problems:}

Just as in traditional commerce, the basic condition in electronic commerce is the users' trust to the system. In a commercial procedure necessitating any contract or electronic communication even just for information transfer, the users (individuals or companies) on rightful grounds do not want third parties accessing to their private personal / corporate information, namely commercial, financial. Besides in communication that is open to third parties aside from privacy of personal data, integrity of transferred information (or in other words receiving the knowledge as it is originally) and confirmation of the identities of parties should also be guaranteed. The condition, which is being discussed in terms of technique and basic human rights, is to utilize which technique, administrative and legal tools to guarantee desired levels of privacy, information integrity and identity confirmation. Unless they are provided in sufficient levels, global development of electronic commerce will be affected significantly (Sadowski, 2002, p. 81).

Safety problems SMEs can face in commercial activities during electronic commerce operations can be expressed as indicated below (Palvia and Palvia, 1999):

- Access to web sources, which have no access authority,

- Damaging information and web resources,

- Changing, mixing or making additions to information,

- Transferring information to unauthorized personnel,

- Stealing information and web sources,

- Denying purchased services, transmitted or received information,

- Claiming to have received or transferred information, not received or transferred at all (Kraemer and Carayon, 2007).

According to the estimations in U.S.A., the value of the data stolen in one year is above 10 billion US dollars. As stated in a research conducted in 1996 on 1320 firms; 78\% of participants declared to have lost money due to safety break, $63 \%$ asserted to have faced loss due to viruses, and 20 users stated to have lost at least 1 million US dollars (Singh and Frolick, 2000, p. 58).

\section{General Review}

Developments in electronic commerce provide brand new advantages in terms of SMEs information technologies usage and access to global markets. However, SMEs have many problems including lack of technological infrastructure and locality, language, infrastructure, environment, legal, safety as categorized under two groups namely technical and cultural. Except U.S.A. and Singapore, which are developed countries regarding information technologies and electronic commerce, SMEs stick to the "wait and see" policy in many other countries. Governments and certain international organizations concerned with this issue have been working on comprehensive projects on a global scale to enable active participation of SMEs in electronic commerce. Furthermore, the fact that SMEs free themselves from traditional commerce practices and adopt new methods thoroughly seems to be closely related to the drive in market conditions and transformation in current business culture. 
Prospective contributions that will emerge with electronic commerce implementations in SMEs are presented below (Burgess, 2002, p. 79; Kotler, 2000, p. 519; Mehrtens et al., 2001, p. 169):

Improved customer base: Enterprises may implement their electronic commerce activities without any regional boundaries, time or country limits. Hence, they may obtain important advantages in global activity by carrying their operations across the borders of region and country.

Time saving in delivery of product and services: Industrial market movement of goods and delivery time may cause great commercial problems. Since almost any enterprises avoids keeping stocks and thus order only when necessary, delivery time gains more attention. Web-based orders, compared to traditional orders, are provided and processed more quickly.

Increased sales: An increase trend in the sales of enterprises is observed at the end of electronic commerce process. Increased sales incomes are even more important for small enterprises. Online sales to customers, order chances and online check of the status of orders would add to customer satisfaction and sales.

Deactivation of mediators: The spread of Internet based electronic commerce has deactivated the mediators operating from producer to customer in the supply chain. Hence, producers offer cheaper, quicker goods and services to customers. Continuous and more appropriate information flow is attained.

Increased customer satisfaction: One of the most important outcomes of electronic commerce is increased customer satisfaction and service level. Because of electronic commerce, customers receive products and services on time; acquire online information, are connected directly to a customer based communication system. The needs of customers are determined by customers themselves and thus increase customer satisfaction.

Improved efficiency and reduced costs: Decreased use of paper and manual operations, automation of ecommerce, news, business and operation processes play vital roles in reducing operation costs of enterprises.

Increased competition: Because of Internet, all enterprises regardless of their size, acquire equal conditions while accessing their customers. By electronic commerce, SMEs will be able to compete against large-scale enterprises with their recognized trademarks, purchase power, and mature structure (Poon and Swatman, 2000, p. 247).

Decrease in Order Processes and Bureaucracy: It is inevitable that once orders are transferred to the Internet, the size of personnel will decrease as compared to the traditional method of receiving and registering orders. In the same way, due to electronic works in place of paper work, enterprises will focus on stocks and inventory and search new ways to develop more creative cooperation with their suppliers. In this way, simplification occurs in routine orders processes and repeated works are automated. Thus, unnecessary applications are eliminated.

Trained customers: Electronic commerce will enhance cognitive literacy of customers and thus they become intellectually more capable. In order to make use of electronic commerce, customers are expected to possess Internet knowledge and computer skills.

Trained employees: Electronic commerce has positive effects on knowledge accumulation of employees as well. To ensure the success of electronic commerce, continuous training programs should be implemented and employees should adapt to the organizational transformation introduced by electronic commerce.

Basic economic effect of electronic commerce is that it creates an economic activity area where handicaps are less in number. This particular effect is basically an outcome generated by rapidly developing information technologies. Since electronic commerce uses this rapidly developing infrastructure, it will have such a great effect on economic life as well. Electronic commerce integrates potentially all the producers, suppliers, users and customers. Hence, it may be acknowledged that it is endowed with capabilities providing many forms of satisfaction that has been dreamed ever since the beginning of industrial revolution.

\section{A Study of the Turkish Automotive Supplier Industry}

\subsection{Scope of the Research}

The purpose of this research is to study the influencing factors, obstacles, and reasons for initiating electronic commerce in SMEs that are active in 2008 as suppliers of the Automotive Industry in Turkey. Population being too large in size, the sample of the research is arbitrarily chosen from the data base of TAYSAD, which is the Association of Automotive Suppliers in Turkey. The reasons of referring to the TAYSAD data base are as follows:

a. All organizations active in the industry are legally required to become a member of the Association,

b. its data base is frequently updated, and

c. information about the member profiles is easily accessed. 
Examination of the TAYSAD data base has revealed that 268 organizations are currently registered. The suppliers not fitting the criteria or scale, or currently inactive have been eliminated and thus only 192 organizations are included in the research.

Taysad established in 1978 and a member of Clepa - the European Association of Automotive Suppliers (www.clepa.be) - is the only authorized association representing the suppliers in the Turkish Automotive Industry. The Association is creditable in all automotive part and component transactions by the foreign and domestic organizations.

The product range of the TAYSAD members is sufficient to create 85-90 percent of the Turkish Automotive Industry production locally. The 268 registered members of the Association provide parts and components for the Turkish Automotive Industry and create $65 \%$ of the production and $70 \%$ of the exports. Eighty-five percent of the members are active in the Marmara region, $10 \%$ in the Aegean, and $5 \%$ in the others. The registered 268 companies of TAYSAD employ 72000 workers and provide employment for 127000 people including its suppliers. Fifty-eight registered companies have foreign partners with varying degrees of capital share.

The questionnaires were distributed to 268 companies as e-mail attachments, surface mail, face-to-face interviews, or by invitation to visit the website www.selcuk.edu.tr/zerenler/anket.01.html in the months of May and June 2012. As $31^{\text {st }}$ of July 2012, 192 responses have been received(a response rate of 71.6); but twenty-four of the organizations registered in the data bank of TAYSAD could never be reached. Eighty-five responses were received as e-mail attachments, 42 by surface mail, 36 face-to-face interviews, and 29 by website visits.

\subsection{Findings of the Research}

As it is seen in Table 2, 33.6\% of the organizations involved in the study have been active in the last 10 years. The companies with employment 200 and above are not included in the research. Hence, the study encompasses only small and medium size enterprises. The results illustrate that most of the respondents in the survey are top level professionals.

Table2. Characteristics of the Companies

\begin{tabular}{|l|c|c|}
\hline Operation period & Frequency & Percentile \\
\hline Between 6-10 years & 79 & 41.2 \\
\hline Between 11-25 years & 73 & 38.0 \\
\hline More than 26 years & 25 & 13.0 \\
\hline Between 1-5 years & 15 & 7.8 \\
\hline Total & 192 & 100.0 \\
\hline Status of the respondent & Frequency & Percentile \\
\hline General manager & 51 & 26.6 \\
\hline Information center manager & 47 & 24.5 \\
\hline Marketing manager & 32 & 16.7 \\
\hline Public relations manager & 22 & 11.5 \\
\hline Owner & 17 & 8.9 \\
\hline Information expert & 14 & 7.3 \\
\hline Board member & 9 & 4.5 \\
\hline Total & 192 & 100.0 \\
\hline
\end{tabular}

The implementation level of the electronic commerce instruments in the companies involved in the study is illustrated in Table 3. Comparing the current level to the level three years ago indicates an increase in the implementation of electronic commerce instruments. As is it discussed in the previous sections, significant increases of implementation are expected in the near future as the SMEs gain more awareness. SMEs may gain competitive advantage against large scale enterprises and access to markets at low cost performance through increasing their electronic commerce abilities. As it is known, one of the major obstacles constraining electronic commerce activities of SMEs is distribution systems. However, it is possible to overcome this obstacle through utilizing distribution chains of large scale companies or outsourcing from the service suppliers in this field. 
Table 3. Implementation level of electronic commerce instruments

\begin{tabular}{|c|c|c|c|c|c|c|c|}
\hline \multirow[b]{2}{*}{ Electronic commerce instruments } & \multicolumn{2}{|c|}{ Three years ago } & \multicolumn{2}{|c|}{ Current } & \multirow{2}{*}{  } & \multicolumn{2}{|c|}{ Wilcoxon Test } \\
\hline & Average & $\begin{array}{l}\text { Std. } \\
\text { Dev. }\end{array}$ & Average & $\begin{array}{l}\text { Std. } \\
\text { Dev. }\end{array}$ & & Z & $P$ \\
\hline Internet & 4.36 & 0.68 & 4.83 & 0.84 & 0.47 & -2.172 & $<.001$ \\
\hline Telephone (deck) & 3.92 & 0.72 & 4.02 & 0.90 & 0.1 & -3.264 & $<.001$ \\
\hline Electronic & 3.87 & 0.88 & 4.76 & 0.72 & 0.89 & -4.634 & $<.001$ \\
\hline Fax & 3.76 & 0.64 & 3.28 & 0.94 & -0.48 & -3.268 & $<.001$ \\
\hline Electronic da & 3.41 & 0.82 & 3.56 & 0.88 & 0.15 & -4.264 & $<.001$ \\
\hline Electronic payment and money transfe & 3.29 & 0.90 & 3.85 & 0.73 & 0.56 & -3.825 & $<.001$ \\
\hline Television & 1.63 & 0.74 & 1.72 & 0.96 & 0.09 & -4.106 & $<.001$ \\
\hline Telephone (mobile) & 1.18 & 0.62 & 2.23 & 0.58 & 1.05 & -3.634 & $<.001$ \\
\hline
\end{tabular}

The results in Table 4 indicate that the companies aim to utilize time advantage of electronic commerce for accessing new markets. In general, SMEs face problems in accessing new markets because of reasons such as limited financial resources, insufficiency of qualified labor, and locality of marketing and distribution systems. Electronic commerce seems to provide advantages to overcome these problems. If compared to traditional commerce, SMEs obtain significant benefits of electronic commerce implementation against large scale companies as they move from local markets to global competition. Indeed, SMEs have acquired important advantages against large scale companies through electronic commerce despite the differences among industrial sectors.

Table 4. Importance level of electronic commerce implementation

\begin{tabular}{|l|c|c|}
\hline Opinion & $\begin{array}{c}\text { Arithmetic } \\
\text { average }\end{array}$ & $\begin{array}{c}\text { Standard } \\
\text { deviation }\end{array}$ \\
\hline Accessing new markets & 4.68 & 0.90 \\
\hline Achieving competitive advantage & 4.43 & 1.04 \\
\hline Gaining extra revenues & 4.19 & 0.78 \\
\hline Cost reduction & 3.95 & 0.92 \\
\hline Impact of rivals & 3.76 & 1.07 \\
\hline
\end{tabular}

Note: (i) $n=143$; (ii) In the scale, 1 indicates no impact, 5 definite impact; (iii) Friedman two way ANOVA test $\left(x^{2}=482.256\right.$ and $p<.001)$, the results are statistically significant.

The results in Table 5 reveal that the most important impact of electronic commerce is enhancement of business activities. In addition, issues such as better access to global markets, improvement of customer services, increase of competitiveness, increases in future revenues through creating new products and services, increases in future revenues through creating new products and service, more options provided to customers at cheaper prices, increase of delivery speed, and better inventory performance have provided benefits to companies in their electronic commerce activities. On the other hand, better understanding of customer demands and expectations, better distribution performance, and achievement of more effective knowledge management seem to influence less than the other factors. However, overall all factors being above average indicates that electronic commerce generate some significant effects on SMEs. In fact, electronic commerce implementation has created some positive major impact on areas, which face many problems and limitations. The automotive suppliers industry provides parts to the major industry. Hence, it has a significant value because of its volume of transactions, but limited in terms of its customers. The automotive suppliers industry utilizes the benefits of electronic commerce implementation in order to enhance business, to facilitate business processes, and access to customers.

Table 5. Impact of electronic commerce

\begin{tabular}{|l|c|c|}
\hline Impact & $\begin{array}{c}\text { Arithmetic } \\
\text { average }\end{array}$ & $\begin{array}{c}\text { Standard } \\
\text { deviation }\end{array}$ \\
\hline Enhancement of business activities & 4.17 & 0.92 \\
\hline Better access to global markets & 4.02 & 0.90 \\
\hline
\end{tabular}




\begin{tabular}{|c|c|c|}
\hline Improvement of customer services & 3.86 & 1.02 \\
\hline Increase of competitiveness & 3.77 & 0.84 \\
\hline Increases in future revenues through creating new products and services & 3.55 & 1.06 \\
\hline More options to provided customers at cheaper prices & 3.19 & 1.10 \\
\hline Increase of delivery speed & 3.12 & 0.76 \\
\hline Better inventory performance & 3.04 & 0.88 \\
\hline Better understanding of customer demands and expectations & 2.93 & 1.02 \\
\hline Better distribution performance & 2.85 & 0.94 \\
\hline Achievement of more effective knowledge management & 2.72 & 0.98 \\
\hline
\end{tabular}

Note: (i) $n=173$; (ii) In the scale, 1 indicates no impact, 5 definite impact; (iii) Friedman two way ANOVA test $\left(X^{2}=386.721\right.$ and $p<.001)$, the results are statistically significant.

In Table 6, the importance level of obstacles constraining electronic commerce activities is shown. The companies point out that lack of three dimensional visual, touch effects, and test drives for automobiles and parts is the major obstacle constraining electronic commerce activities. As stated in the previous sections of the study, commodities such as automobile and real estate are not the goods that can be easily purchased because of their value and consumption. Hence, their purchasing process is more complicated and requires longer time as compared to non-durable goods purchased and consumed more frequently. In the light of these circumstances, the situation is quite the same for the products of automotive supplier industry. Even though the model, type, price, and other characteristics of the demanded products are well known by customers and providers, the lack of three dimensional visual, touch effects, and test drives significantly influence electronic commerce just like in traditional commerce activities. However, companies nowadays can easily monitor the products they want to purchase in the Internet and place their orders.

Lack of customization for automobile parts is another major obstacle to foster electronic commerce. However, as mentioned in the previous sections, mass customization practices are increasingly employed in many industrial sectors, including the automotive industry. In the automotive industry, it is extremely important to meet and even exceed customer expectations and needs. Lack of customization for automobile parts as pointed out by the companies may be attributed to an important limitation of technological capability. Hence, the Industry is required to develop its technological infrastructure, qualified manpower, and sophisticated information systems.

Table 6. Importance level of obstacles constraining electronic commerce activities

\begin{tabular}{|l|c|c|}
\hline Obstacle & $\begin{array}{c}\text { Arithmetic } \\
\text { average }\end{array}$ & $\begin{array}{c}\text { Standard } \\
\text { deviation }\end{array}$ \\
\hline Lack of three dimensional visual, touch effects, and test drives for automobiles and parts & 4.43 & 1.88 \\
\hline Lack of customization for automobile parts & 4.29 & 0.94 \\
\hline Internet not being reliable & 3.86 & 0.86 \\
\hline Requirement of Internet address for the companies & 3.71 & 1.04 \\
\hline Lack of technological infrastructure of the major industry & 3.58 & 0.90 \\
\hline Major industry preferring traditional commerce & 3.36 & 1.12 \\
\hline Lack of face-to-face communication with sales people & 3.09 & 0.76 \\
\hline Insufficiency of Internet payment methods & 2.91 & 0.81 \\
\hline Small number of product varieties & 2.85 & 1.02 \\
\hline Poor designed websites & 2.62 & 1.13 \\
\hline Insufficiency of websites & 2.57 & 1.06 \\
\hline
\end{tabular}

Note: (i) $n=192$; (ii) In the scale, 1 indicates no impact, 5 definite impact; (iii) Friedman two way ANOVA test ( $X^{2}=724.363$ and $p<.001)$, the results are statistically significant.

Table 7 exhibits the opinions of the companies about the future of electronic commerce. The companies have pointed out that organizations will become more dependent on electronic commerce in the future. In addition, it is generally agreed that electronic commerce will increasingly provide strategic competitive advantage. SMEs generally consent that electronic commerce will impact organizational structure of the companies radically, be a part of conversion for our business, and already plays a significant role in today's business. 
Table 7. Opinions about the future of electronic commerce

\begin{tabular}{|l|c|c|}
\hline Opinion & $\begin{array}{c}\text { Arithmetic } \\
\text { average }\end{array}$ & $\begin{array}{c}\text { Standard } \\
\text { deviation }\end{array}$ \\
\hline Organizations will become more dependent on electronic commerce. & 4.62 & 1.06 \\
\hline Electronic commerce will provide strategic competitive advantage. & 4.31 & 1.02 \\
\hline Electronic commerce will impact organizational structure of the companies radically. & 4.17 & 1.08 \\
\hline Electronic commerce will be a part of conversion for our business. & 3.79 & 0.92 \\
\hline Currently, electronic commerce is part of our business. & 3.38 & 0.90 \\
\hline
\end{tabular}

Note: (i) $n=192 ;$ (ii) In the scale, 1 indicates not accept, 5 definitely accept; (iii) Friedman two way ANOVA test $\left(X^{2}=682.136\right.$ and $\left.p<.001\right)$, the results are statistically significant.

\section{Conclusion}

Globalization and intensive influence of information technologies renders it indispensable to carry out commercial activities in electronic ways. Small and medium enterprises (SMEs) are increasingly utilizing the electronic commerce for their commercial activities. Hence, electronic commerce is developed almost in every industrial sector as witnessed by the increasing number of examples. It provides too many advantages and benefits to companies and other organizations.

Electronic commerce has significantly transformed the way in which firms conduct business, allowing them to gain more business opportunities and competitive advantage. However, the results from the study have revealed a lack of or slow uptake of electronic commerce technologies among the local SMEs. The objectives of this study were to understand and determine the importance of internal and external barriers; and thus provide support to overcome their problems. Among the different variables studied, technical, financial and social/ cultural barriers have been reported to create significant influence in the context of electronic commerce development in the SMEs.

The study conducted in the Turkish Automotive Supplier Industry has revealed that electronic commerce has been adopted and its benefits are accepted by the companies. However, the industry has to overcome some of the difficulties to implement it more efficiently and effectively.

\section{References}

Bayles, D. (2001), E-Commerce Logistics and Fulfillment: Delivering the Goods, Upper Saddle River, NJ, U.S.A., Prentice Hall PTR.

Burgess, S. (2002), Information Technology in Small Business: Issues and Solutions, in Burgess, S. (Ed.), Managing Information Technology in Small Business: Challenges and Solutions, 1-17. Hershey, PA: Idea Group Publishing.

Calin G. Ranchhod, A. \& Hackney, R. (2001). "Internet Transactions and Physical Logistics: Conflict or Complementary", Internet Research: Electronic Networking Applications and Policy, Volume 14, Number 1/2, s. 36

Chaffey, D. (2007), E-business and E-commerce Management-Strategy, Implementation and Practice, 3th ed. Harlow: Pearson Education.

Chaston, I. (2001). "The Internet and E-Commerce: An Opportunity to Examine Organisational Learning in Progress in Small Manufacturing Firms?" International Small Business Journal 19(2), 13-30.

Chen, A. H. \& Siems, T. (2001), "B2B eMarketplace Announcements and Shareholder Wealth", Economic and Financial Review, First Quarter.

Chen, S. (2004), Strategic Management Of E-business, John Wiley.

Colombo, M.G. (2001). "Technology-Based Entrepreneurs: Does Internet Make a Difference?", Small Business Economics, 16(3), 177190.

Combe, C. (2006), Introduction To E-business: Management And Strategy, Butterworth-Heinemann Inc.

Coppel, J. (2000). E-commerce: Impacts and Policy Challenges, OECD Economics Department Working Papers, no.252

Dandridge, T. (2000). "High-Tech Potential? An Exploratory Study Of Very Small Firms' Usage of the Internet", International Small Business Journal, 18(2), 81-91.

Daniel, E., Wilson, H. \& Myers, A. (2002). "Adoption of Ecommerce by SMEs In The UK: Towards a Stage Model", International Small Business Journal, 20(3), 253-270.

Dans, E. (2001). "IT Investment in Small and Medium Enterprises:Paradoxically Productive?" The Electronic Journal of Information Systems Evaluation, 4 (1).

Davis, P.S. (2000). "Internationalization and Organizational Growth: The Impact of Internet Usage and Technology Involvement Among Entrepreneur-Led Family Businesses", Family Business Review, 13(2), 107-120.

De Bono, E. (1994). Sur/petition, New York, HarperCollins Publishers Ltd.

Delone, W. H. (1988). "Determinants of Success for Computer Usage in Small Business", MIS Quarterly, No:1, Vol:12, 1988, 51-61. 
Dornan, A. (2001). The Essential Guide to Wireless Communications Applications, New Jersey:Prentice Hall.

Eikebrokk, T. R. \& Olsen D. H. (2007). "An Empirical Investigation of Competency Factors Affecting e-business Success in European SMEs", Information \& Management, 44, 364-383.

Evans, P.B. \& Wurster, B.S. (1997). "Strategy and the new Economics of Information", Harvard Business Review, 75(5), 70-83.

Farhoomand, A. \& Lovelock, P. (2001), Global E-commerce: Text and Cases, Prentice Hall, New York.

Fischer, M. (2000). "Using E-commerce to Deliver High Productivity", Work Study, vol. 49, no. 2, 59-62.

Gottschalk, P. (2005), E-Business Strategy, Sourcing and Governance, Idea Group Publishing, London.

Hawkins, R. and Prencipe, A. (2000). Business-to-Business E-Commerce in the UK: A Synthesis of Sector Report, Department for Trade and Industry, London.

Heijden, H.v.d. (2000), "The Inclusion of E-commerce Metrics in Strategic Planning: Results from an Exploratory Empirical Study", Proceedings of the Americas Conference on Information Systems, Long Beach, CA.

Heinen, J. (1996), "Internet Marketing Practices", Information Management \& Computer Security, Vol. 4 Number 5, pp. 7-14

Janenko, P. M. (2003), E-business: The Illusion of Automated Success, The TQM Magazine, 15 (3).

Jelassi, T. \& Enders, A. (2008), Strategies for e-business :Creating Value through Electronic and Mobile Commerce : Concepts and Cases, Harlow:FT Prentice Hall.

Kalakota, K. \& Whinston, A. (1997). Electronic Commerce, Addison Wesley Longman, Inc., U.S.A.

Kapurubandara, M. and Lawson, R. (2006) "Barriers to Adopting ICT and e-commerce with SMEs in Developing Countries: an Exploratory Study in Sri Lanka", Collecter, (Collaborative Electronic Commerce Technology and Research), December 2006, UniSA, Adelaide.

Kleindl, B. (2000). "Competitive Dynamics and New Business Models For SMEs in the Virtual Marketplace", Journal of Developmental Entrepreneurship, 5(1), 73-85.

Kotler, P. (2000). Marketing Management, The Millenium Edition, Prentice Hall, N. J. 2000.

Kraemer, S. \& Carayon, P. "Human errors and violations in computer and information security: The viewpoint of network administrators and security specialists", Applied Ergonomics, 2007, 38(2): 143-154.

Kshetri, N. (2007). "Barriers to e-commerce and competitive business models in developing countries: A case study", Electronic Commerce Research and Applications, 6, (2007), 446.

Kurnia, S. \& Johnston, R. B. (2000), "The Need for a Processual view of Inter-Organizational Systems Adoption", Journal of Strategic Information Systems, 9(4) 295-319.

Lai, J. \& Chen W. (2009), "Measuring E-business Dependability: The Employee Perspective", Journal of Systems and Software, 82(6): 1046-1055.

Levy, M., Powell, P. \& Galliers, R., 1999, "Assessing Information Systems Strategy Development Frameworks in SMEs", Information \& Management, 36 (5), 247-261.

Levy, M., Powell, P. \& Yetton, P. 2001, "SMEs:Aligning is and the Strategic Context", Journal of Information Technology, 16,133-144.

Li, J. (2006), "Chinese Entrepreneurship and Small Business Development: An Overview and Research Agenda," Journal of Small Business and Enterprise Development, 13(2).

Liew, V. (2009). E-Commerce Usage by the SMEs in Northern Malaysia: Analysis of the State of E-Commerce Adoption by the SMEs in Northern Malaysia and Factors that Might Hinder its Adoption: An Empirical Study, VDM Verlag.

MacGregor R. C. \& Vrazalic, L. (2005). "A Basic Model of Electronic Commerce Adoption Barriers", School Of Economics and Information Systems, University of Wollongong, Australia, 515-529.

MacGregor, R. C. (2008). The Adoption of E-commerce in SMEs: The Role of Strategic Alliances, VDM Verlag.

MacGregor, R.C. (2004). "The Role of Strategic Alliances in The Ongoing Use of Electronic Commerce Technology in Regional Small Business", Journal of Electronic Commerce in Organizations, 2 (1), 1-14.

Mehrtens, J., Cragg, P.B. \& Mills, A.M. (2001). "A model of Internet Adoption by SMEs", Information \& Management, 39(3), $165-176$.

Nusair, K. \& Hua, N. (2009),"Comparative Assessment of Structural Equation Modeling and Multiple Regression Research Methodologies: E-commerce Context", Tourism Management, xxx, 1-11.

Oyelaran-Oyeyinka, B. \& Kaushalesh L. K. (2004). Internet Diffusion in sub-Saharan Africa:a cross-country Analysis, Telecommunications Policy.

Palvia, P.C. \& Palvia, S.C. (1999), "An examination of the IT Satisfaction of Small-Business Users", Information and Management, Number 35, pp.127-137.

Peterson, R. A.; Balasubramanian, S. \& Bronnenberg, B. J. (1997). "Exploring the Implications of the Internet for Consumer Marketing", Journal of Academy of Marketing Science, Vol:25, No:4.

Poon, S. \& Swatman, P. (2000). "Internet-based Small Business Communication: seven Australian cases", Electronic Markets, Vol. 7(2), 241-259.

Porter, M. (2001). "Strategy and the Internet", Harvard Business Review, March, 63-78.

Quayle, M. (2002). "E-Commerce: the challenge for UK SMEs in the twenty-first century", International Journal of Operations \& Production Management, 22 (10), 1148-1161.

Reynolds, J. \& Mofazali, R. (2000), The Complete E-commerce Book: Design, Build and Maintain a Successful Web-based Business, McGraw-Hill Inc.,US.

Rowley, J. (2002), E-business: Principles and Practice, New York: Palgrave. 
Sadowski, B.M. (2002). "Strategic Use of the Internet by Small and Medium-Sized Companies: an Exploratory Study", Information Economics and Policy, 14(1), 75-93.

Singh, C. \& Frolick, M. N. (2000). "Ibuttons : Building the Infrastucture for more Secure E-commerce", Infrormation Systems Security, Winter, Vol 8 Issue 4, ss. 56-59.

Singh, M. \& Waddell, D. (2006), E-business Innovation and Change Management, Idea Group Publishing.

Soliman, F. \& Youssef, M. A. (2003). "Internet-Based E-Commerce and Its Impact On Manufacturing and Business Operations", Industrial Management and Data Systems,103/8, 546-552.

Stansfield, M. \& Grant, K. (2003). "An Investigation Into Issues Influencing the use of the Internet and Electronic Commerce among Small-Medium Sized Enterprises", Journal of Electronic Commerce Res, 4(1), 15-28.

Stockdale, R. \& Standing, C. (2004),"Benefits and barriers of electronic marketplace participation: an SME perspective", Journal of Enterprise Information Management, 17(4), pp, 301-311.

Strader, T. J. \& Ramaswami, S. N. (2002), "The Value of Seller Trustworthiness in C2C Online Markets," Communications of the ACM, 45:12(December), 45-49.

Varianini, V. \& Vaturi, D. (2000), "Marketing Lessons from e-failures", McKinsey Quarterly, № 4.

Van Beveren, J. (2002). "The Use of Electronic Commerce by SMEs in Victoria, Australia", Journal of Small Business Management, 40(3), 250-253.

Vinberg, S., Gelin, G. \& Sandberg, K. (2000), "Information Technology Levels, Competence Development and Performance in Swedish Small Business Enterprises", Behaviour and Information Technology, C:19, S:3.

Walczuch, R., Van Braven, G. \& Lundgren, H. (2000). "Internet Adoption Barriers for Small Firms in the Netherlands", European Management Journal, 18(5), 561-572.

Warren, M. \& Hutchinson, W. (2005) "A Systems Approach to Security", in Kurt a Richardon, Wendy J Gregory \& Gerald Midgley (eds), Systems Thinking and Complexity Science: Insights for Action Proceedings of the 11th Annual ANZSYS / Managing the Complex $\checkmark$ conference, ISCE Publishing, New Zealand

Webb, B. \& Sayer, R. (1998). "Benchmarking Small Companies on the Internet", Long Range Planning, 31(6), 815-827.

Williamson I. O. Lepak, D. P. \& King, J. (2003). "The effect of company recruitment web site orientation on individuals' perceptions of organizational attractiveness", Journal of Vocational Behavior, 63(2), 242-263.

Zerenler, M. (2007). Dijital İş Yaşamı: Tüm Boyutlarıyla Elektronik Ticaret (Digital BusinessLife: Electronic Commerce with all its Dimensions), (in Turkish), Ankara, Gazi Kitabevi (Gazi Bookstore).

Zhao, F. (2006), Entrepreneurship and Innovations in E-business: An Integrative Perspective, Idea Group Publishing.

http://www.theblognote.com/zapposcom-ornek-bir-e-ticaret-basari-hikayesi.html Access date: 10.06.2009.

http://www.ogilvy.com.tr/digitalmarketingcompass/ Access date: 07.08.2009. 